\title{
Entrepreneurship: structural transformation, skills and constraints
}

\author{
Ralitza Dimova $\cdot$ Kevwe Pela
}

Accepted: 7 July 2017 /Published online: 4 September 2017

(C) The Author(s) 2017. This article is an open access publication

\begin{abstract}
This paper revisits the place of the entrepreneur in the process of structural transformation and economic development, using representative data from Nigeria. The focus is on the allocation of self-employed individuals with different skill levels across sectorsprimary, secondary and tertiary — and on its link to selectivity corrected returns to skills in these sectors. While self-employment is dominated by service sector activities and these activities attract more skilled individuals than do the manufacturing and primary sectors, the level of skills across all three entrepreneurial sectors is lower than that of both salaried workers and individuals who do not work. Returns to skills among selfemployed individuals in the manufacturing sector are particularly low. This is at least partially explained by constraints to productive entrepreneurial activities and is inconsistent with the idea of smooth structural transformation towards innovative entrepreneurship. We discuss some conceptual and policy implications.
\end{abstract}

Keywords Entrepreneurship · Structural transformation · Economic development $\cdot$ Nigeria

JEL classification $\mathrm{J} 22 \cdot \mathrm{J} 24 \cdot \mathrm{N} 80 \cdot \mathrm{O} 14$

R. Dimova $(\bowtie) \cdot K$. Pela

Global Development Institute, University of Manchester,

Manchester, UK

e-mail: Ralitza.Dimova@manchester.ac.uk

\section{Introduction}

Following decades of research, the definition of "entrepreneurship" remains elusive (Nieman 2006). Historically, entrepreneurship has been associated with individuals' ability to identify and capitalise on opportunities. Economies with higher numbers of entrepreneurs were believed to outpace economies with smaller numbers (Venter et al. 2010). According to Filion (1997), entrepreneurial activities date back to as early as the seventeenth century which witnessed the emergence of new industrial firms. Early analysts like Jean Baptiste Say (1836) defined the entrepreneur of that era as a self-employed individual engaging in risky and profitable activities and creating value. The spirit of such earlier notions of entrepreneurship prevails in current definitions. OECD (1997) and Zimmerer and Scarborough (2008) define entrepreneurship as a form of self-employed activity that identifies opportunities and creates new ventures.

In line with this perception, earlier theoretical frameworks have seen entrepreneurship as a key driver of economic development, irrespective of whether the entrepreneur herself epistomises the process of growth-enhancing innovation (Schumpeter 1934) or is somebody who identifies profitable ideas that have already been introduced successfully to the market (Kizner 1976). While also seeing the entrepreneur as a promoter of economic development, others focus on her place in the process of structural transformation. For instance, drawing on the experience of currently developed economies, Porter et al. (2002) describe the different roles played by entrepreneurs across three stages of economic development, namely (i) a factor- 
driven stage, characterised by a dominant primary sector and unqualified labour force, (ii) an efficiency-driven stage, in which entrepreneurship drops because large firms hire most of the workforce, and (iii) an innovation-driven stage, in which the service sector becomes more important and the start up of new businesses, producing sophisticated products, increases. Ács and Naudé (2013) build upon this framework and see the link between economic development and innovative entrepreneurship as an S-shape type relationship. In the early, factor-driven stage of development the level of innovative entrepreneurial activities is low, accounting for no more than 5\% of economic activities, but rises to $10 \%$ in the efficiency-driven stage and $30 \%$ in the innovation-driven stage. Moving onwards through the stages, the importance of knowledge accumulation and absorption increases.

The structural transformation-based conceptual framework of entrepreneurship is very helpful for understanding the synergy between skill development and entrepreneurial innovation as economies develop. It is also extremely helpful in understanding the historical development of entrepreneurship among currently advanced economies. It is interesting to try to answer the question to what extent it is useful as a basis for analysis and policy advice for a range of countries that are currently undergoing or about to undergo structural transformation. To begin with, this conceptual framework shies away from giving an explicit answer to the question of whether-following the example of currently advanced economies - countries starting at relatively low levels of income need to experience an efficiency-driven industrialisation stage before moving to a high skilled service-based economy. Fundamental classical theories of industrialisation-based economic development such as those of Rosenstein-Rodan (1943), Murphy et al. (1989) and Kaldor (1967) emphasise key advantages of manufacturing over services in the form of economies of scale, backwards, forward linkages and innovative potential. The role of the super-entrepreneur in achieving a "big (industrialisation based) push" a la Rosenstein-Rodan (1943) is fundamental.

At the same time, overwhelming evidence of urbanisation without industrialisation, as well as premature deindustrialisation in large parts of the less developed world, especially Africa and Latin America, casts doubts on the potential of contemporary less developed economies (and entrepreneurs within these economies) to capitalise on traditional modes of industrialisation options (Gollin et al. 2015; Rodrik 2016). While entrepreneurial success stories such as the ICT sector in India offer a service sector based way forward in an era of manufacturing decline, a number of analysts question the employment (and innovation) augmenting potential of skill intensive services as an alternative to large scale manufacturing (Rodrik 2016; Szirmai 2009). Moreover, although stimulus for small business creation continues to be seen as a panacea to high levels of unemployment in contexts characterised by a significant decline of salaried employment (Dimova et al. 2016), there is evidence suggesting that the vast majority of small businesses in less developed countries share closer resemblance to hidden unemployment than dynamic entrepreneurship (Margolis 2014). Furthermore, marco level (cross-country) studies highlight higher positive correlation of national incomes with dominant salaried employment than with a dominant (secondary and tertiary sector based) small business sector (Margolis 2014). Indeed, in more contemporary research on motives behind self-employment, it is common to distinguish between opportunitydriven, dynamic type of entrepreneurship and necessitydriven self-employment that is more akin to hidden unemployment even within developed country contexts (Blanchflower 2004; Poschke 2013). Although investigating the motives behind entrepreneurship is not the primary concern of research on the role of the entrepreneur in the process of structural transformation, it is important to take into account at least the stylised variety of forms and nuances of entrepreneurial activities in order to grasp fully their economic development potential.

Irrespective of the modalities of self-employment, if potential entrepreneurs find it difficult to locate opportunities with high returns to skills and innovation, this would have obvious bearing on not only the utilisation of accumulated human capital but also on incentives for future human capital accumulation. Although much of the post1960s international development agenda has prioritised investment in education as a key policy objective, there is evidence from several parts of the world that unemployment among highly educated youth is on the rise (Dimova et al. 2016; Kouakou 2011). There is also evidence to suggest that — on average - returns to skills are lower in the generally largest (non-agricultural) self-employment sector in less developed countries than in salaried employment, and there is high correlation between low availability of skill intensive job opportunities and low returns to skills, on the one hand, and low incentives to acquire skills, as well as high drop out rates from schooling, on the other (Dimova et al. 2010). The evidence suggests that a large proportion of the less developed part of the world may be undergoing a structural transformation, dominated by 
transition from primary to tertiary sector- - largely low skill activities - that is starkly different from a smooth transition from primary to efficiency led secondary and thereafter innovation-driven tertiary sector entrepreneurship. This highlights a potential scope for rethinking the contemporary applicability of traditional models of relatively smooth structural transformation and on the role of the entrepreneur in that transition.

In this paper, we revisit the issue of structural transformation in the process of economic development and the role of the entrepreneur and skill acquisition in this process with the use of evidence from Nigeria. Since the December 3, 2011 issue of the "Economist" described Africa as a "hopeful" continent, "Africa rising" has become a buzzword in both academic and policy circles. One of the highlights of this discussion is the fact that six out of the ten fastest growing countries in the world today are in Africa. Much of these countries' success is attributed to entrepreneurial activities, technological advances and fledgling manufacturing and service sectors. Among African countries, the case of Nigeria was flagged as a success story when a rebasing exercise led to estimates of a GDP of US\$509 billion, making Nigeria the largest economy in Africa and the 26th largest in the world (World Bank 2014). Importantly, recent statistics revealed the economy as much more diversified than that highlighted in earlier estimates. Although oil and gas as well as sectors that service the local market (agriculture, trade, food and various services) continue to be important, these are estimated to account for only $54 \%$ of the Nigerian output (compared to earlier estimates of $84 \%$ ). Sectors such as telecommunications, real estate, manufacturing, construction and entertainment are becoming increasingly important. In the context of these positive developments, the role of the entrepreneurial small and medium business sector is seen as catalytic in the achievement of Nigeria's Vision 2020 to be among the 20 most industrialised economies by 2020 (Kadiri 2012). For the purposes of this study, it is particularly illuminating to note that the latest Global Competitiveness Report defines Nigeria as one of 17 countries in transition from factor-based to efficiency-based economy (World Economic Forum 2017).

At the backdrop of these positive developments, economic health continues to be dependent on the oil sector, as indicated by the budgetary and growth difficulties experienced in the aftermath of the sharp decline in oil revenues upon fall of oil prices between June 2014 and January 2015 (Barungi et al. 2015). Although the sheer size of the small and medium enterprise sector has increased dramatically - by $14.3 \%$ from $32,414,844$ to $37,067,416$ in just 3 years between 2010 and 2013 — estimates indicate that close to half of the working age population is unemployed (Small and Medium Enterprises Development Agency of Nigeria 2013). There is also concern that the quality of education provided may not be at par with the potential of the economy to innovate. Indeed, the same Global Competitiveness Report that identifies Nigeria as being in transition from factor to efficiency-based economy also gives its education and skill base a rank of 122 out of 135 countries. This raises the question of what proportion of the SME sector is truly entrepreneurial as opposed to a form of hidden unemployment.

The main purpose of this paper is to reconcile conflicting views in the broad conceptual literature on entrepreneurship and conflicting evidence on economic diversification and entrepreneurship in the process of structural transformation in Nigeria with the aim of drawing some generalisations and policy recommendations. Using a sophisticated econometric methodology, we first explore the allocation of labour belonging to different skill groups across different entrepreneurial sectors - primary, secondary and tertiary - salaried employment and not working and the related returns to skills across the different entrepreneurial sectors, after correcting for potential selection biases. This exercise helps us establish (i) whether entrepreneurs are a negatively selected sample of the overall working age population or, in other words, possess observed and unobserved characteristics inferior to those of salaried workers and non-working individuals and (ii) whether there are niches within the secondary and/or tertiary entrepreneurial sectors, which attract high skill workers and provide high returns to observed skills, thus creating incentives for acquisition of such skills among potential labour market entrants. We supplement this empirical exercise with detailed statistics that help us go beyond the averages inherent in an econometric analysis and delve further into the specific characteristics of entrepreneurs and their specific occupations. As a robustness check in the empirical analysis, we also present a version that distinguishes between stylised categories of entrepreneurs, namely those who employ and those who do not employ workers from outside the family as proxies of opportunity and necessity entrepreneurs, respectively.

The rest of the paper is organised as follows. Section 2 describes the econometric methodology used for the core empirical analysis. Section 3 describes the data and highlights some preliminary descriptive statistics. Results from the core econometric analysis are highlighted in Section 4, 
and these are supplemented in Section 5 with results from more detailed descriptive analysis and further robustness checks based on differentiation between necessity and opportunity entrepreneurs. Section 6 concludes.

\section{Empirical methodology}

Our key objective is to assess the link between allocation of entrepreneurs with different skill levels across sectors - primary (agriculture), manufacturing and services - and the returns to these skills in each of these sectors. This relationship is captured by the following system of equations:

$Y_{s}=X_{s} \beta_{s}+U_{s}$

$Y_{s}^{*}=Z_{s} \gamma_{s}+\eta_{s}, s=1 \ldots M$

where $Y_{S}$ refers to earnings associated with each sector, while $Y_{s}^{*}$ is a discrete choice variable, indicating the sector of allocation of entrepreneurs. Equation [2] is estimated using a multinomial logit model, while $U_{s}$ satisfies $E\left(U_{s} \mid X\right)=0$ and $V\left(U_{s} \mid X, Z\right)=\sigma^{2}$.

Note that if we rely on an OLS model, each of the latent (wage) Equations in [1] would be estimated separately. As such, for each of the sectors of interest to us, we can use stylised Mincer type specification, where the key regressors in the wage-skill relationship are measures of observed skills, such as education. We can thus produce estimates of returns to skills in the primary, secondary and tertiary entrepreneurial sectors, ignoring the fact that individuals may not be randomly selected into each of these sectors. However, given that choosing an employment sector is unlikely to be a result of a random process - such that $U_{s}$ and $\eta_{s}$ are not independent - the least squares estimates of $\beta_{s}$ would be biased.

To correct for this potential bias, we use the Bourguignon, Fournier and Gurgand's (BFG) methodology (2001). This leads to the modification of Eq. [1] into:

$Y_{i}=X_{i} \beta_{i}+\sigma_{i}\left[\rho_{i} m\left(P_{i}\right)+\sum_{j \neq i} \rho_{i} \frac{P_{j}}{\left(P_{j}-1\right)} m\left(P_{j}\right)\right]+v_{i}$

where $\beta_{i}$ are the bias-corrected estimates of returns to individual attributes in each of the entrepreneurial sectors of interest, while $X_{i}$ is the vector of these attributes. The key difference between Eqs. [1] and [3] is the added $\sigma_{i}\left[\rho_{i} m\left(P_{i}\right)+\sum_{j \neq i} \rho_{i} \frac{P_{j}}{\left(P_{j}-1\right)} m\left(P_{j}\right)\right]$ term, which identifies the direction of the selectivity bias. Notationally, $m\left(P_{s}\right)$ represent the probabilities of ending in any one of the possible sectoral choices, while $\left(\sigma_{1} \rho_{1} \ldots \ldots \ldots \sigma_{s} \rho_{s}\right)$ are the corresponding estimates of selectivity bias associated with each respective sector.

Intuitively, these selectivity correction coefficients tell us whether entrepreneurs that end in say the manufacturing sector are either positively or negatively selected in that sector compared to entrepreneurs allocated to either the agricultural or the service sectors. If, for instance, we see that the selection coefficient associated with service sector employment in the earnings equation of entrepreneurs allocated in the manufacturing sector is negative and significant, we would argue that entrepreneurs in the manufacturing sector are negatively selected compared to those employed in the service sector. Their unobserved skills are more appropriate for employment in the service sector, but they are misallocated to the manufacturing sector. In other words, aside from providing unbiased estimates of returns to observed skills, such as education, the BFG method allows us to indirectly assess the influence of unobserved skills (such as being inherently entrepreneurial), which are difficult to measure, but tend to play an important role in the allocation of entrepreneurs across employment opportunities.

As discussed at the outset of this section, our main interest is in assessing the allocation of entrepreneurs across entrepreneurial sectors and their returns to skills in those sectors. However, if we only focus on the sample of entrepreneurs, we would be working with a selected sample due to the fact that entrepreneurs are not randomly selected from the working age population at large. To correct for this additional source of selectivity, we work with the full sample of working age individuals but include two additional choices in the first stage of our empirical model, those accounting for allocation of individuals into salaried employment and into not working. In addition to helping us alleviate the potential selectivity problem, these labour market choices allow us to find out whether entrepreneurs are positively or negatively selected (or, in other words, have either superior or inferior observed and/or unobserved characteristics) compared 
to those allocated in the salaried sector and those who are not employed. This aligns neatly with development economics literature which tries to answer the question of whether self-employment is a form of dynamic entrepreneurship (Maloney 1999, 2004) or whether instead it is more akin to hidden unemployment (Mazumdar 1983; Fields 1990).

In sum, we estimate the following system of equations:

$$
\begin{aligned}
{\left[\text { LnWages }=\alpha_{0}\right.} & +\sum\left(\alpha_{1 i} \text { Education }\right)+\alpha_{2} \text { Age } \\
& +\alpha_{3} \text { Female }+\alpha_{4} \text { Year }+\alpha_{5} \text { Urban }+u
\end{aligned}
$$

$$
\begin{aligned}
\text { Sector }= & \beta_{0}+\sum\left(\beta_{1 i} \text { Education }\right)+\beta_{2} \text { Age }+\beta_{3} \text { Female } \\
& +\beta_{4} \text { Year }+\beta_{5} \text { Urban }+\beta_{6} \text { FathernotAgriculture }+\beta_{7} \text { MothernotAgriculture } \\
& +\beta_{8} \text { AccesstoBank }+\beta_{9} \text { ClosenesstoMarket }+\beta_{10} \text { AccesstoTranportation }+v
\end{aligned}
$$

where as discussed earlier, the Sector variable in [5] includes the following categories: (i) Entrepreneur in Agriculture, (ii) Entrepreneur in Manufacturing, (iii) Entrepreneur in Services, (iv) Salaried Employee and (v) Individual that does not work. It is estimated with the use of a multinomial logit model. Equation [4], in turn, gives unbiased estimates of returns to entrepreneurial skills in the three sectors of entrepreneurial allocation considered, where in each case we are able to assess whether entrepreneurs in the sector of interest are positively or negatively selected compared to individuals in the remaining four labour market categories. While the earnings equations's specification is a version of a stylised Mincer equation, following related literature (Dimova et al. 2010; Dimova and Karim 2016) in the selection equation, we include variables that directly affect the choice of a sector but do not directly (other than through the choice of a sector of employment) affect the earnings of entrepreneurs. These include the sector of employment of mothers and fathers of the respondent (as a proxy of intergenerational transfer of occupational status) and infrastructural variables, capturing whether the community of residence of the respondent has access to a bank and public transportation, as well as whether that community is close to a market. Given that the majority of respondents' parents were employed in the agricultural sector, we use dummy variables of whether either the father or the mother of the respondent had employment outside of agriculture. Aside from serving as excluded variables for the identification of our system, the infrastructural variables are key proxies of entrepreneurial constraints. In keeping with the literature on the links between access to finance and industrialisation and in particular the part of this literature, exploring the constraints faced by entrepreneurs in both entering profitable manufacturing sector niches and being able to grow after they create a business (Kerr and Nanda 2009), we are particularly interested in the effect of the access to finance variable in our selection equation. Since a household level version of this variable in the employment selection equation would be endogenous, we rely on a community level version. The choice of these infrastructural variables is consistent with those identified by the World Economic Forum (2017) as constraints to entrepreneurial activities that can plausibly be measured at the community level.

\section{Data and preliminary statistics}

The empirical analysis in this paper is based on the Living Standards Measurement Survey (LSMS) of the World Bank. This is a general household survey, established in the early 1980s in collaboration with statistical offices around the world, generating high quality representative household data. The Nigerian surveys were conducted in collaboration with the National Bureau of Statistics and the Bill and Melinda Gates Foundation in 2010/2011 and 2012/2013. The two waves can be used either as a panel or as individual cross-sections. Given the nature of our econometric model, we do not exploit the panel element but simply pool the two annual cross-sections together and 
include a yearly dummy variable to account for a time fixed effect.

The dataset is fairly rich. Aside from very detailed consumption/expenditures and incomes modules, it provides very detailed demographic information, as well as labour market/occupational information and community characteristics. To ensure consistency with the labour economics literature, we limit our samples to exclude individuals who fall outside the working age population. The sample for this study thus only includes individuals in the 15-65 age group. Due to data limitations in the recording of hours of work, we use monthly (take home) incomes as a proxy for earnings from entrepreneurial and nonentrepreneurial activities. In keeping with the definition of entrepreneurs, highlighted at the outset, we define entrepreneurs as individuals involved in self-employed activities. We then further categorise the occupational sectors of entrepreneurs in three different groups: agriculture, manufacturing and services. ${ }^{1}$ Given the limited number of observations in high education categories, we club different degrees together and capture educational attainment by two different categories: "complete primary education and incomplete secondary education" and "complete higher secondary and above". This allows us to avoid inconsistencies in the recall of actual years of education and is consistent with alternative specification that we attempted. The omitted category includes entrepreneurs with no education or with informal education. All infrastructural variables are taken from the community module and are dummy variables indicating whether there is either a bank or a market in the enumeration area and whether the enumeration area has access to public transport.

Figure 1 highlights the sectoral allocation of entrepreneurs. We see that the self-employment sector is dominated by services. The service sector accounts for $52 \%$ of the self-employed activities. At the same time, the manufacturing sector accounts for only $8 \%$ of the self-employed activities. This pattern is not necessarily inconsistent with the Porter et al. (2002) conceptual framework whereby the efficiency-driven (typically manufacturing based) stage of the structural transformation process is characterised by entrepreneurial decline

\footnotetext{
${ }^{1}$ Note that only a minuscule number (two to three) entrepreneurs defined themselves as belonging to the oil sector- perhaps not surprisingly due to the largely capital intensive nature of that sector and hence the low ability to capture such entrepreneurs in a representative household survey. We therefore dropped them from our analysis. But allocating them to the agricultural primary sector did not significantly change our results.
}

due to dominance of large firms hiring most of the workforce. At the same time, additional statistics from Nigeria (and the majority of the rest of the African continent) indicate that the low level of selfemployment in manufacturing is a reflection of the low level of manufacturing activities overall (across both self and salaried employment), alongside dominance of service sector-based non-agricultural employment (The World Bank 2013). The pattern is more consistent with trends of premature de-industrialisation than low level of small and medium sector manufacturing activities due to a manufacturing sector dominance by large firms.

Table 1 reports some key characteristics of entrepreneurs in the agricultural, manufacturing and service sectors and compares them with the characteristics of salaried employees and labour force members who do not work. One of the most interesting observations is the fact that self-employed individuals are significantly less educated than both salaried employees and those who do not work. While more than a quarter of the salaried individuals and the individuals who do not work have completed secondary or tertiary education, a significantly smaller percentage of those who are self-employed have these higher educational degrees. Self-employed people in the agricultural and in the manufacturing sectors have the lowest levels of education (only approximately $9 \%$ of those in the manufacturing sector have completed secondary education or above and this is true for only $10 \%$ of those in the agricultural sector). The incidence of secondary or higher education among self-employed individuals in the service sector is slightly higher - approximately $18 \%$ - but even then less than that of salaried employees and those who do not work. The cross-sectoral educational differences are less stark when looking at individuals who have completed primary or some secondary education, but even then, education is lowest among self-employed individuals in the manufacturing sector.

The educational distributions across sectors are consistent with the pattern of cross-sectoral average incomes: on average, incomes in the salaried sector exceed those of self-employed individuals; while among self-employed individuals those employed in the service sector earn more than those in the other two sectors. Taken together, these patterns are consistent with evidence elsewhere in Africa whereby low returns to skills, especially in the dominant sector of self-employment, discourages individuals from pursuing higher levels of education (Dimova et al. 2010). In addition to interesting patterns 
Fig. 1 Sectoral distribution of entrepreneurs

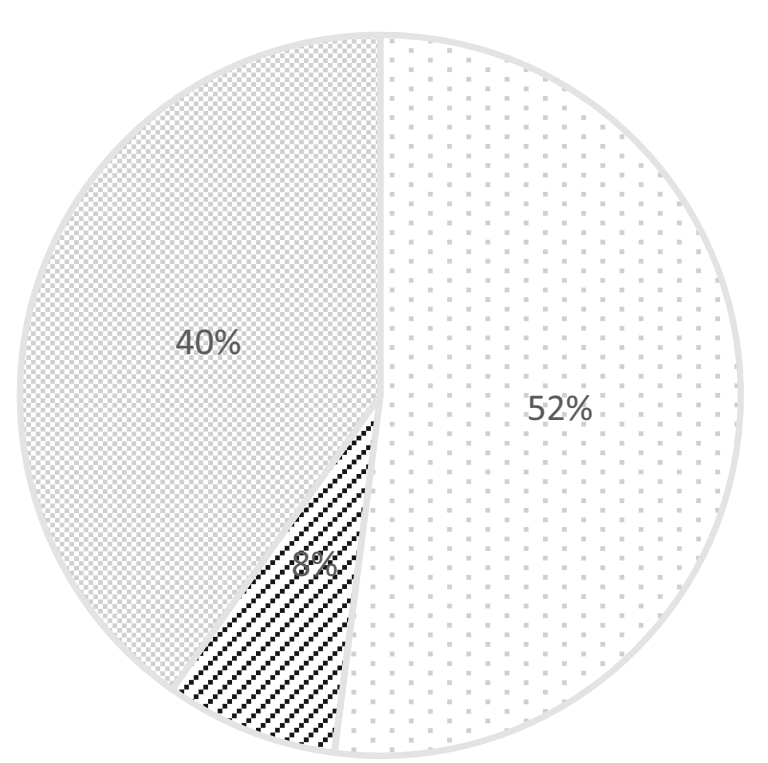

Agriculture $\odot$ Manufacturing Services related to the key variables of interest to us, namely education and earnings, we observe interesting differences in the means of the infrastructural variables across sectors. Perhaps most interestingly, the mean of the access to a bank variable is significantly lower in the service self-employment sector than in the rest of the sectoral categories. It is possible that better educated individuals allocate to the service sector not because of better (average) opportunities but because of constraints that prevent them from allocating into more capital intensive sectors. In the next section, we shall explore this possibility in greater rigour.

Table 1 Descriptive statistics

\begin{tabular}{llllll}
\hline & $\begin{array}{l}\text { Entrepreneur } \\
\text { agriculture }\end{array}$ & $\begin{array}{l}\text { Entrepreneur } \\
\text { manufacturing }\end{array}$ & $\begin{array}{l}\text { Entrepreneur } \\
\text { services }\end{array}$ & Salaried & Not working \\
\hline Age & $39.3646(13.9726)$ & $36.3069(11.4131)$ & $39.0021(12.1847)$ & $36.3696(12.7733)$ & $27.8410(12.1066)$ \\
Primary or incomplete secondary & $0.2676(0.4427)$ & $0.2019(0.4016)$ & $0.2839(0.4509)$ & $0.2943(0.3957)$ & $0.2486(0.4322)$ \\
Complete higher & $0.1054(0.3071)$ & $0.0898(0.2861)$ & $0.17884(0.3832)$ & $0.2678(0.4429)$ & $0.2530(0.4347)$ \\
$\quad$ secondary or above & $0.4116(0.4921)$ & $0.8229(0.3818)$ & $0.6267(0.4836)$ & $0.4398(0.4964)$ & $0.5921(0.4914)$ \\
Female & $0.0740(0.2619)$ & $0.1770(0.3818)$ & $0.2991(0.4579)$ & $0.2738(0.4459)$ & $0.1927(0.3944)$ \\
Father (non-agriculture) & $0.2376(0.4256)$ & $0.6494(0.4773)$ & $0.5530(0.4972)$ & $0.3667(0.4819)$ & $0.2995(0.4580)$ \\
Mother (non-agriculture) & $0.2441(0.4295)$ & $0.2363(0.4252)$ & $0.1978(0.3984)$ & $0.2183(0.4131)$ & $0.2316(0.4218)$ \\
Access to bank & $0.5783(0.4938)$ & $0.5765(0.4943)$ & $0.5800(0.4935)$ & $0.5526(0.4972)$ & $0.5824(0.4931)$ \\
Closeness to market & $0.4421(0.4966)$ & $0.4395(0.4965)$ & $0.4778(0.4995)$ & $0.4413(0.4966)$ & $0.4643(0.4987)$ \\
Access to transportation & $0.0723(0.2591)$ & $0.2766(0.4475)$ & $0.4531(0.4978)$ & $0.3971(0.4893)$ & $0.3549(0.4785)$ \\
Urban & $0.4612(0.4985)$ & $0.5258(0.4995)$ & $0.5470(0.4978)$ & $0.5831(0.4930)$ & $0.4877(0.4998)$ \\
2012/2013 & $9.1468(1.1256)$ & $9.0432(1.2001)$ & $9.6345(1.1872)$ & $10.1739(1.1460)$ & \\
Log monthly income & 7730 & 1154 & 5971 & 4461 & 14,032 \\
Observation & & & &
\end{tabular}

The figures in brackets are standard deviations 
Table 2 Multinomial logit 2010-2013

\begin{tabular}{llllll}
\hline & $\begin{array}{l}\text { Entrepreneur } \\
\text { agriculture }\end{array}$ & $\begin{array}{l}\text { Entrepreneur } \\
\text { manufacturing }\end{array}$ & $\begin{array}{l}\text { Entrepreneur } \\
\text { services }\end{array}$ & Salaried & Not working \\
\hline Age & $0.0066^{\mathrm{a}}(0.0001)$ & $0.0002(0.0000)$ & $0.0059^{\mathrm{a}}(0.0001)$ & $0.0033^{\mathrm{a}}(0.0001)$ & $-0.0162^{\mathrm{a}}(0.0002)$ \\
Primary or incomplete & $0.0100^{\mathrm{b}}(0.0051)$ & $-0.0047^{\mathrm{a}}(0.0019)$ & $0.0751^{\mathrm{a}}(0.0064)$ & $0.0179^{\mathrm{a}}(0.0054)$ & $0.0402^{\mathrm{c}}(0.0077)$ \\
$\quad$ secondary & $-0.1000^{\mathrm{b}}(0.0051)$ & $-0.0161^{\mathrm{a}}(0.0020)$ & $0.0125^{\mathrm{b}}(0.0070)$ & $0.0650^{\mathrm{a}}(0.0068)$ & $0.0386^{\mathrm{b}}(0.0086)$ \\
Complete higher & $-0.1335^{\mathrm{a}}(0.0046)$ & $0.0326^{\mathrm{a}}(0.0019)$ & $0.0620^{\mathrm{a}}(0.0045)$ & $-0.0638^{\mathrm{a}}(0.0043)$ & $0.1027^{\mathrm{a}}(0.0061)$ \\
$\quad$ secondary or above & $-0.0988^{\mathrm{a}}(0.0053)$ & $0.0094^{\mathrm{a}}(0.0018)$ & $0.0498^{\mathrm{a}}(0.0062)$ & $0.0628(0.0062)$ & $-0.0043(0.0081)$ \\
Female & $-0.0806^{\mathrm{a}}(0.0044)$ & $0.0413^{\mathrm{a}}(0.0026)$ & $0.1222^{\mathrm{a}}(0.0053)$ & $0.0201^{\mathrm{a}}(0.0045)$ & $-0.0627^{\mathrm{a}}(0.0067)$ \\
Father (non-agriculture) & $0.0217(0.0058)$ & $0.0055^{\mathrm{c}}(0.0024)$ & $-0.0340(0.0056)$ & $-0.0010^{\mathrm{a}}(0.0056)$ & $0.0078(0.0079)$ \\
Mother (non-agriculture) & $-0.0005(0.0019)$ & $0.0021^{\mathrm{a}}(0.0053)$ & $0.0101^{\mathrm{b}}(0.0050)$ & $-0.0088^{\mathrm{b}}(0.0072)$ \\
Access to bank & $0.0003^{\mathrm{b}}(0.0051)$ & $\left.-0.00635^{\mathrm{a}}\right)$ \\
Closeness to market & $0.0215^{\mathrm{b}}(0.0053)$ & $-0.0063(0.0020)$ & $-0.0229^{\mathrm{a}}(0.0055)$ & $-0.0036^{\mathrm{a}}(0.0052)$ & $0.0086^{\mathrm{a}}(0.0074)$ \\
Access to transportation & $-0.2326^{\mathrm{b}}(0.0041)$ & $0.0018^{\mathrm{a}}(0.0017)$ & $0.0869^{\mathrm{a}}(0.0053)$ & $0.0373^{\mathrm{a}}(0.0047)$ & $0.1102^{\mathrm{a}}(0.0068)$ \\
Urban & $-0.0588^{\mathrm{a}}(0.0045)$ & $-0.00245^{\mathrm{a}}(0.0017)$ & $0.0376(0.0048)$ & $0.0615(0.0046)$ & $-0.0379^{\mathrm{a}}(0.0065)$ \\
2012/2013 & 1154 & 5971 & 4461 & 14,032 \\
Observation & 7730 & &
\end{tabular}

The results reported are marginal effects. The figures in brackets are standard errors. The results meet the independent and irrelevant alternative conditions. IIA test results are reported in Appendix Table 9

${ }^{a}$ Significance at $1 \%$

${ }^{\mathrm{b}}$ Significance at $5 \%$

${ }^{\mathrm{c}}$ Significance at $10 \%$

\section{Empirical results}

Tables 2 and 3 highlight the results from our rigorous empirical analysis. Table 2 reports the marginal effects from the multinomial logit model on labour allocation across salaried employment, not working and the three entrepreneurship sectors of interest to us - agriculture, manufacturing and services - while Table 3 presents the

Table 3 Earnings estimations

\begin{tabular}{llll}
\hline & Entrepreneur agriculture & Entrepreneur manufacturing & Entrepreneur services \\
\hline Age & $0.0213(0.0157)$ & $-0.0165^{* * *}(0.0416)$ & $-0.0130(0.0140)$ \\
$\begin{array}{l}\text { Primary or incomplete } \\
\quad \text { secondary }\end{array}$ & $0.2388^{* * *}(0.2163)$ & $0.0725(0.9896)$ & $0.16889 * * *(0.1309)$ \\
Complete higher & $0.6339(0.7538)$ & $0.8890(1.5957)$ & $0.1378 * *(0.2679)$ \\
$\quad$ secondary or above & $-0.0981^{* * *(0.5059)}$ & $-0.7140(1.4201)$ & $0.5038(0.1830)$ \\
Female & $1.3116^{* * *(0.9404)}$ & $0.2383(0.4480)$ & $-0.3550(0.1808)$ \\
Urban & $0.1171^{* *}(0.0553)$ & $-0.3020(0.0981)$ & $-0.1954(0.0378)$ \\
2012/2013 & $-1.1413(1.0047)$ & $-0.5569(3.6821)$ & $-2.6920^{* * *}(0.7236)$ \\
M1 & $0.3758(2.9587)$ & $0.6572 * *(2.8437)$ & $0.7365(1.9795)$ \\
M2 & $2.2641(1.6327)$ & $-2.4815(4.7811)$ & $-0.6686(0.4332)$ \\
M3 & $-1.3340(2.2263)$ & $1.1312(0.6411)$ & $-4.0692 * * *(1.1793)$ \\
M4 & $-1.8196^{* *}(1.7378)$ & $1.7305(0.1535)$ & $-0.6039) 1.1448$ \\
M5 & $8.4812^{* * *(1.1358)}$ & $9.1644(1.7436)$ & $8.9752(1.5105)$ \\
Cons & 0.0856 & 0.3471 & 0.2089 \\
$R$-squared & 7730 & 1154 & 5971 \\
Observation & & & \\
\hline
\end{tabular}

The figures in brackets are standard errors

$* * *, * *$ and $*$ indicate significance at the $1 \%, 5 \%$ and $10 \%$ level, respectively 
estimates of returns to different types of education, after accounting for potential biases due to non-random allocation of people across the different labour market sectors. Recall that our main interest is in finding out whether entrepreneurs are able to locate skill intensive niches in the entrepreneurial market, especially in the secondary and tertiary sectors, and obtain high returns to their observed skills. Indirectly, answering this question-especially in comparison to the allocation of labour to salaried employment and not working-will also indicate whether the entrepreneurial sector is dynamic, with potential to generate innovation, or whether it is instead a form of hidden unemployment.

The marginal effects of the complete secondary or higher education variable are negative and significant in the agricultural and manufacturing sectors and positive and significant in salaried employment and the service entrepreneurial sector. In addition, the marginal effects of the complete primary or some secondary education variable are positive and significant in all but the manufacturing sector equation. The marginal effect of both educational variables is negative and significant in the manufacturing entrepreneurial sector, highlighting the clear negative selectivity - based on observed skills - into that sector. Furthermore, while the marginal effect of completed secondary education and above is positive and significant in the service sector, the size of this effect is substantially smaller than that if the marginal effect of this variable in the salaried employment sector and even in the sector of not working. Overall, high levels of education do not matter-in fact have negative implications - for being self-employed as opposed to salaried employed, except in the service sector which tends to host relatively educated self-employed people.

Infrastructural variables have significant impact on labour allocation across sectors, with the expected sign. The marginal effect of access to finance is positive and significant in the potentially most capital intensive manufacturing entrepreneurial sector but is negative and significant in the salaried employment sector. This is consistent with evidence that access to finance is one of the largest constraints to productive entrepreneurship in less developed countries. At the same time, closeness to markets has positive impact on being self-employed in either the agricultural sector or the service sector as well as on being salaried employee and has negative effect on not working, while access to transportation matters most for entrepreneurs in the agricultural sector. As expected, family background also plays important role for labour allocation, with all coefficients having the expected signs. The overall message is that having parents with non-agricultural employment has positive implications on children's non-agricultural employment, either as self-employed individuals or as salaried employees. In sum, the story from this stage of the analysis is that tinkering with policy variables, such as those related to infrastructural - and in particular financial sector-development, may have positive implications for the creation of productive entrepreneurial sector niches. At the same time, in keeping with the descriptive statistics presented in the previous section, there is paucity of high skill opportunities in the entrepreneurial sector.

The results from the second stage of the empirical analysis (Table 3) are consistent with the story emanating from the first stage. Both educational variables are positive and significant only in the service sector. In the agricultural sector, completed primary and incomplete secondary education provides positive returns, while none of the educational variables are significant in the manufacturing sector. Age has significant (and negative) effect only on self-employment in manufacturing. ${ }^{2} \mathrm{Un}$ observed characteristics appear to have stronger effect on returns to skills in the three different selfemployment sectors than do observed skills, as indicated by the significance of the selectivity correction variables. Perhaps most interestingly, the selectivity correction term associated with agricultural self-employment in the service self-employment equation is negative and significant, highlighting a negative selection out of agriculture into services. In other words, self-employed individuals who would have performed better in the agricultural sector allocate into the service sector. The same is true for the coefficient associated with salaried employment in the service sector equation, suggesting that capable individuals may be queuing up for salaried jobs, but instead opt for self-employed activities in the service sector. This is consistent with dual market models of structural transformation and casts some doubts on the success of structural transformation.

\footnotetext{
$\overline{{ }^{2} \text { Experimenting }}$ with non-linearity in the age-employment relationship indicated that the effect is linear.
} 


\section{Further empirical analysis and discussion}

\subsection{Further insights from alternative descriptive} statistics

The analysis conducted so far is based on average estimates across the five different employment sectors of interest to us. Among the key findings is the fact that salaried employment is the one sector that both attracts individuals with high levels of education and provides significant positive returns to that education. Among selfemployment sectors, only the service sector appears to be a profitable venue for skilled individuals, suggesting that the country may be skipping the industrialisation stage of the stylised structural reform process and moving straight away to the stage of de-industrialisation. At the same time, skilled labour allocation in that sector is inferior to that of salaried employment — as witnessed by both the descriptive statistics and the more rigorous empirical analysis. This is consistent with the fact that the wage distribution in the salaried self-employment sector lies substantially to the left of that for salaried employees, although it is clearly to the right of self-employed individuals in the manufacturing and agricultural sectors (Fig. 2). In other words, the deindustrialisation process in Nigeria does not obviously share the characteristics of successful de-industrialisation in the process of structural reform, described by Porter et al. (2002).

To overcome the constraints of working with sectoral averages and get more detailed insight into the nature of work across the different self-employment sectors and salaried employment, Table 4 delves deeper into the concrete occupational niches within which individuals across salaried employment and the three self-employment sectors operate. We see that within manufacturing, the dominant sub-sectors are food, beverages and tobacco, textiles, apparel and footwear and wood and wood products, all of which tend to be at the bottom of the value chain and hence associated with low skill activities. This is consistent with the results from our empirical analysis in that the manufacturing self-employment sector attracts both some of the lowest skill individuals and provides low returns to skills. Moreover, the incidence of salaried employment in the manufacturing sector is low, which is contrary to traditional models of industrialisation, characterised by large-scale manufacturing production.

While professional and scientific occupations are available in the self-employment service sector, roughly at par with the incidence of these same types of occupations in the salaried sector, they represent a minuscule fraction of the overall range of job opportunities. Indeed, the selfemployment service sector is by far dominated by buying and selling activities, followed by personal services, neither of which is known for high levels of skill intensity and innovation capacity. The service sector does absorb some professionals and education and health specialists, but their representation in that sector is minuscule compared to the dominant two sets of activities. By contrast, the dominant salaried sector is that of public administration, followed by the education sector. While high skills and corresponding adequate earnings in a countries' public
Fig. 2 Monthly income distribution across sectors. Kernel densities for monthly income 2010/2013

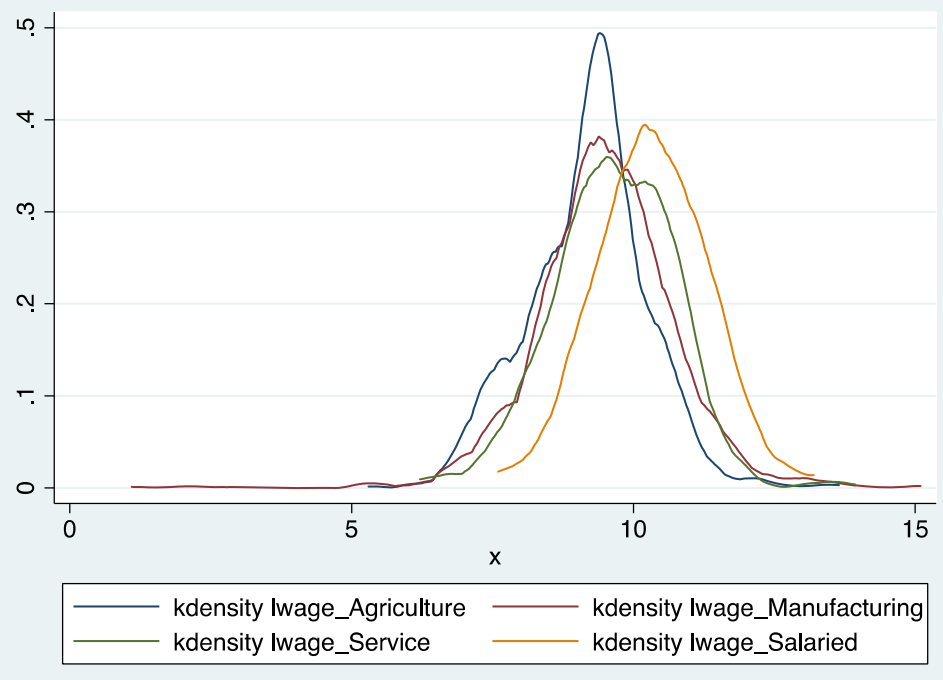


Table 4 Types of activity

\begin{tabular}{|c|c|c|c|c|}
\hline & Agriculture & Manufacturing & Services & Salaried \\
\hline Agriculture & 7730 & 0 & 0 & 1591 \\
\hline Manufacturing (food, beverage and tobacco) & 0 & 583 & 0 & 62 \\
\hline Manufacturing (textiles, apparel and footwear) & 0 & 424 & 0 & 25 \\
\hline Manufacturing (wood and wood products) & 0 & 120 & 0 & 24 \\
\hline Manufacturing (chemical and pharmaceutical products) & 0 & 15 & 0 & 1 \\
\hline Manufacturing (plastic and rubber products) & 0 & 10 & 0 & 3 \\
\hline Manufacturing (electronic) & 0 & 2 & 0 & 10 \\
\hline Professional/scientific & 0 & 0 & 190 & 250 \\
\hline Electricity/water/gas/ & 0 & 0 & 14 & 45 \\
\hline Transportation & 0 & 0 & 310 & 190 \\
\hline Buying and selling & 0 & 0 & 3460 & 261 \\
\hline Financial/insurance/real estate & 0 & 0 & 20 & 55 \\
\hline Personal services & 0 & 0 & 1340 & 229 \\
\hline Education & 0 & 0 & 181 & 643 \\
\hline Health & 0 & 0 & 144 & 215 \\
\hline Public administration & 0 & 0 & 176 & 710 \\
\hline Other service activities & 0 & 0 & 136 & 147 \\
\hline Observation & 7730 & 1154 & 5971 & 4461 \\
\hline
\end{tabular}

The figures reported are numbers of observations per cell

administration sector are important for strengthening of countries' institutions and governance, absorbing a disproportionate part of the skilled workforce in that sector may have a crowding out effect on innovative private sector activities. In comparison, salaried sectors like health - that are inherently skill intensiveare relatively smaller.

Table 5 highlights some further information, some of which needs to be interpreted with caution, due to the fact that on occasion - for instance with respect to whether entrepreneurs hire people from outside the family or not - there are a lot of missing observations. The information provided is generally inconsistent with the perception of self-employment as a sector of dynamic entrepreneurship. While one of the most popular definitions of a dynamic entrepreneur is one of an entrepreneur who is able to expand her business and create employment (Chen 2014; Margolis 2014), we see that the majority of entrepreneurs in our sample do not hire anyone from outside the family, while only a handful hire between one and five labourers. The propensity of entrepreneurs to export is also very low and the majority of self-employed individuals sell directly to final customers as opposed to exploring forward and downward linkages. Finally, a dominant proportion of self-employed individuals either work from home or at a roadside, which is characteristic of some of the worst forms of employment (Chen 2014).

5.2 Further conceptual insights and empirical robustness checks

To provide further insights into the nature of entrepreneurship in Nigeria, especially given the conceptually mixed results so far on entrepreneurship in the service sector, we delve even deeper into the notion of necessity versus opportunity entrepreneurship highlighted at the outset of the paper. Specifically, we use one of the most popular stylised ways of differentiating between necessity and opportunity entrepreneurs in the literature (Poschke 2013) whereby the former are defined as self-employed individuals who expand their businesses by hiring labour from outside the family, while the latter are own account self-employed individuals who do not hire any non-family labourers. We thereafter call the first group of self-employed people "employers" and the second group "own account self-employed". The focus is on whether these two different groups of entrepreneurs are fundamentally different. As indicated in the preceding section, due to a relatively large incidence of absence of 
Table 5 Further characteristics

Agriculture Manufacturing Services

\begin{tabular}{|c|c|c|c|}
\hline \multicolumn{4}{|c|}{ Where do they sell their products } \\
\hline Home (inside resident) & 1363 & 523 & 1322 \\
\hline $\begin{array}{l}\text { Home (outside } \\
\text { resident) }\end{array}$ & 558 & 155 & 1119 \\
\hline Industrial site & 18 & 15 & 71 \\
\hline Traditional market & 550 & 79 & 930 \\
\hline Commercial area shop & 133 & 66 & 622 \\
\hline Roadside & 139 & 33 & 314 \\
\hline Other fixed place & 80 & 24 & 222 \\
\hline $\begin{array}{l}\text { Mobile/no fixed } \\
\text { location }\end{array}$ & 350 & 36 & 580 \\
\hline Other & 40 & 4 & 37 \\
\hline \multicolumn{4}{|c|}{ Who do they sell their products to } \\
\hline Final consumers & 2664 & 804 & 4743 \\
\hline Traders & 602 & 118 & 613 \\
\hline Other small businesses & 222 & 55 & 277 \\
\hline Large established bus & 32 & 7 & 64 \\
\hline $\begin{array}{l}\text { Institution } \\
\text { (i.e. schools) }\end{array}$ & 29 & 4 & 67 \\
\hline Export & 14 & 0 & 2 \\
\hline Manufacturers & 11 & 4 & 22 \\
\hline \multirow[t]{2}{*}{ Other (specify) } & 84 & 6 & 128 \\
\hline & 3658 & 998 & 5916 \\
\hline \multicolumn{4}{|c|}{$\begin{array}{l}\text { Number of hired workers who } \\
\text { are not family members }\end{array}$} \\
\hline None & 2113 & 817 & 3862 \\
\hline $1-5$ people & 560 & 154 & 859 \\
\hline 6-10 people & 9 & 4 & 31 \\
\hline 10 and above & 15 & 2 & 14 \\
\hline
\end{tabular}

The figures reported are numbers of observations per cell

response to the question of whether these selfemployed individuals hire labourers, the results should be treated with caution and are therefore only reported in the Appendix.

Looking first at the descriptive statistics based on this differentiation (Table 6 in the Appendix), we see that - as expected - among non-agricultural self-employed individuals, employers tend to be characterised by greater incidence of completed secondary or higher education than own account self-employed individuals. Employers in the service sector are also characterised by higher incidence of completed primary or some secondary education than their own account counterparts, but the opposite is true for the incidence of completed primary education of their manufacturing sector counterparts. There are no other very remarkable differences across the two different types of self-employed individuals, except that (consistently with their higher levels of education) employers tend to earn slightly more than own account individuals, though once again significantly less than salaried employees.

Tables 7 and 8 in the Appendix highlight the corresponding multinomial logit and earnings equations. Once again, the conceptual distinction with respect to Tables 2 and 3 is the differentiation between employers and own account individuals among the self-employed in each of the three entrepreneurial sectors. The marginal effects from the multinomial logit model reveal some interesting distinctions among the two categories of self-employed individuals. Perhaps most interestingly, while the complete secondary education or above variable has positive and insignificant effect on being an employer in the service sector, the effect of this variable on becoming own account self-employed individual in the service sector is negative and significant. This is consistent with our expectations based on the literature indicating that employers are better endowed opportunity entrepreneurs, while own account self-employed individuals are more likely to be necessity entrepreneurs. At the same time, the marginal effects of this higher education variable are negative and significant in all the remaining entrepreneurial niches, although their sizes are larger among employers in the agricultural and manufacturing sector than among their own account counterparts. By contrast, the marginal effects of the secondary or higher education variable are positive and significant in both the salaried workers' and non-working individuals' equations. For all types of self-employed individuals, the marginal effect of the primary or some secondary education variable is positive and significant in the agricultural sector and the service sector but negative and significant among employers in the manufacturing sector. This is yet another indication of the negative selection of entrepreneurs in the manufacturing sector. In sum, the association between education and labour market allocation gives further support to the general finding that self-employed individuals as a whole are a negatively selected sample of the overall working age population.

The rest of the results from the multinomial logit model are consistent with their Table 2 counterparts. Among the most interesting highlights is perhaps the fact that the access to a bank variable has a positive impact on becoming an employer in the manufacturing sector but has no significant effect on becoming an own account individual, once again emphasising the importance of access to 
finance for becoming productive entrepreneur in this capital intensive sector.

Finally, the earnings estimates highlighted in Appendix Table 8 are consistent with those in Table 3, whereby only in the service sector self-employed individuals obtain significant positive returns to higher levels of education, while in the agricultural sector self-employed individuals obtain significant positive returns to completed primary or incomplete secondary education. In both cases, the returns are significantly higher among employers than among own account individuals. With respect to selectivity, based on unobserved characteristics, perhaps the most clear, visible and easiest to interpret pattern is that of the negative selection of self-employed individuals in the manufacturing sector out of the self-employed service sector. This is consistent with the rest of the story emanating from our empirical research.

\section{Concluding comments and extensions}

Using representative data from Nigeria, this paper revisits the place of the entrepreneur in the process of structural transformation and economic development from the point of view of an economy that has undergone significant movement out of the primary employment sector but is at a relatively low position in the global industrial value chain, has a small manufacturing sector and is dominated by a service sector that is the largest absorber of relatively skilled self-employed individuals. In doing so, we cast fresh light on theories of entrepreneurship that see the link between entrepreneurship and broader forms of economic development in concrete structural transformation stages, whereby exit from the primary sector and growth of selfemployment in the secondary and service sectors is seen as proxy for successful economic development. While the self-employment sector is dominated by service sector activities and these activities attract more skilled individuals than do the self-employed manufacturing and primary sectors, the level of skills across all the three entrepreneurial sectors is lower than that of both salaried workers and individuals who do not work. Allocation of skilled labour and returns to skills among entrepreneurs in the manufacturing sector are particularly low.

Aside from skill allocation patterns, there are several additional signs that the self-employment as a whole is more akin to necessity than opportunity entrepreneurship. The majority of businesses either do not hire outside labour or hire no more than five workers, exemplifying limited growth potential of the entrepreneurial sector and hence limited potential of exploiting economies of scale. There are high infrastructural - in particular credit related - constraints to allocation of labour into potentially productive occupations. Moreover, while models of economic development through industrialisation emphasise the advantage of backwards and forwards linkages, our evidence suggests that such linkages are limited in the Nigerian context. This is contrary to a stylised view of successful structural reform led by either efficiency or innovation, highlighted at the outset, and is consistent with evidence from elsewhere in the Global South, in particular the rest of the African continent (Margolis 2014; Chen 2014; Böhme and Thiele 2014; Dimova et al. 2010).

As the evidence on infrastructural and credit constraints to business growth is pervasive in the literature on entrepreneurship in less developed countries, this literature agrees on at least two related productive ways forward. On the one hand, there is a consensus that releasing financial constraints would stimulate investment in capital-intensive sectors and activities (The World Bank 2008). At the same time, evidence on positive implications of ensuring access to finance on (small) firm performance and growth is inconclusive (Grimm 2016; Karlan and Morduch 2010). Indeed, there is evidence that, in risky environments, individuals that are wealthy and hence not credit constrained tend to over-invest at the start of their business but adjust their capital stocks downwards subsequently (Grimm et al. 2011). This suggests that lifting financial constraints alone may not be a panacea when the institutional setting does not provide adequate risk management mechanisms. On the other hand, authors argue that the problem of infrastructural constraints is best addressed in the context of industrial clusters. In the current state of globalisation and de-coupling of production, where exploiting manufacturing economies of scale within a single national geographical context may be limited, the potential of industrial clusters for entry and movement up a value chain should certainly not be underestimated. This idea however clashes with counterarguments that the evidence of success with broad-based development and movement up the technological ladder on account of industrial clusters and value chains is either limited or unequal (Yusuf 2003; Brookings 2015).

One proposition that not only receives increasing consensus in the conceptual literature on economic development but also has large amount of support from historical evidence is that fundamental institutional change is a necessary ingredient to broad-based economic development (Shirley 2008; North et al. 2009; Rodrik 2008). This gives 


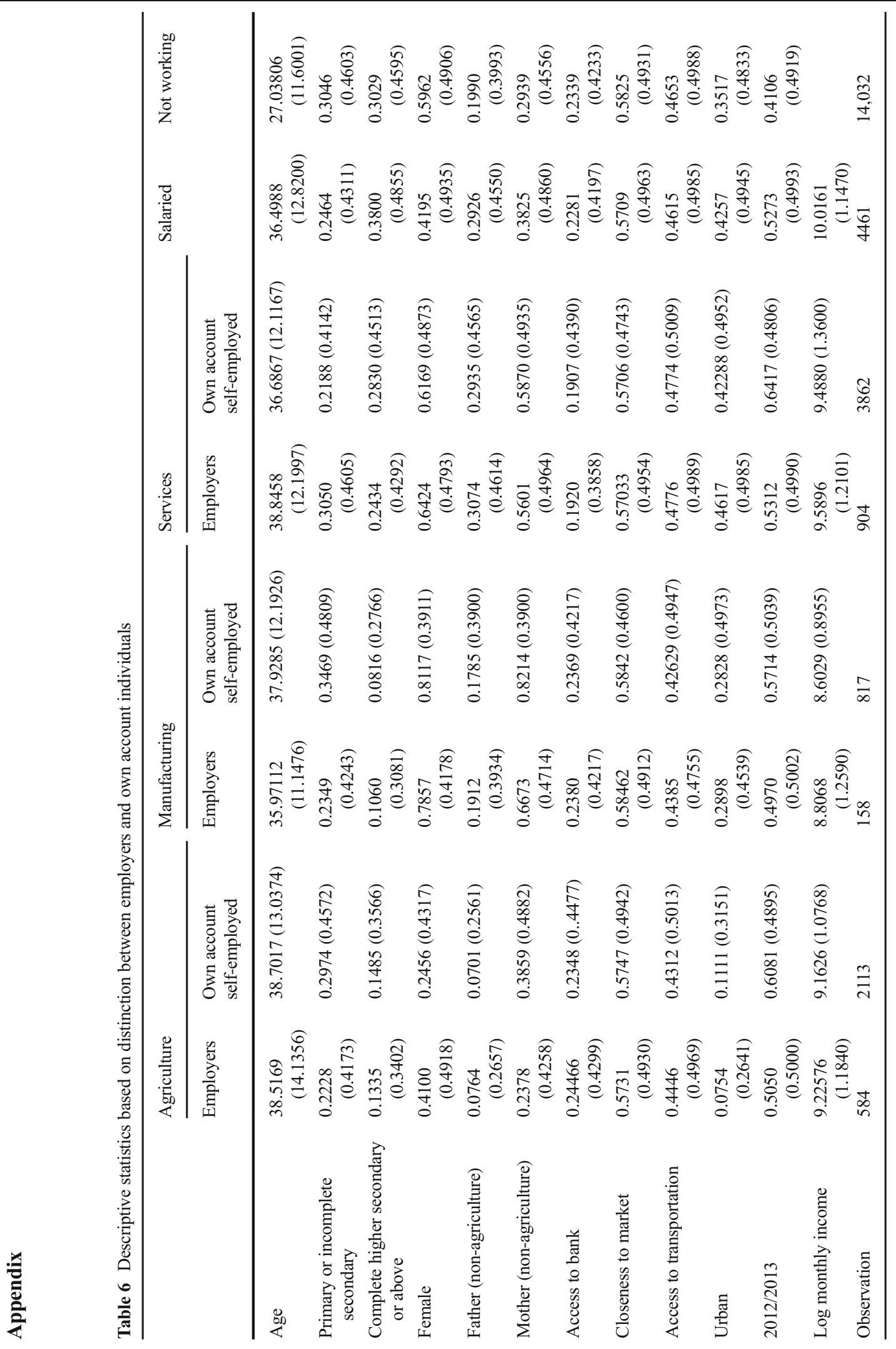




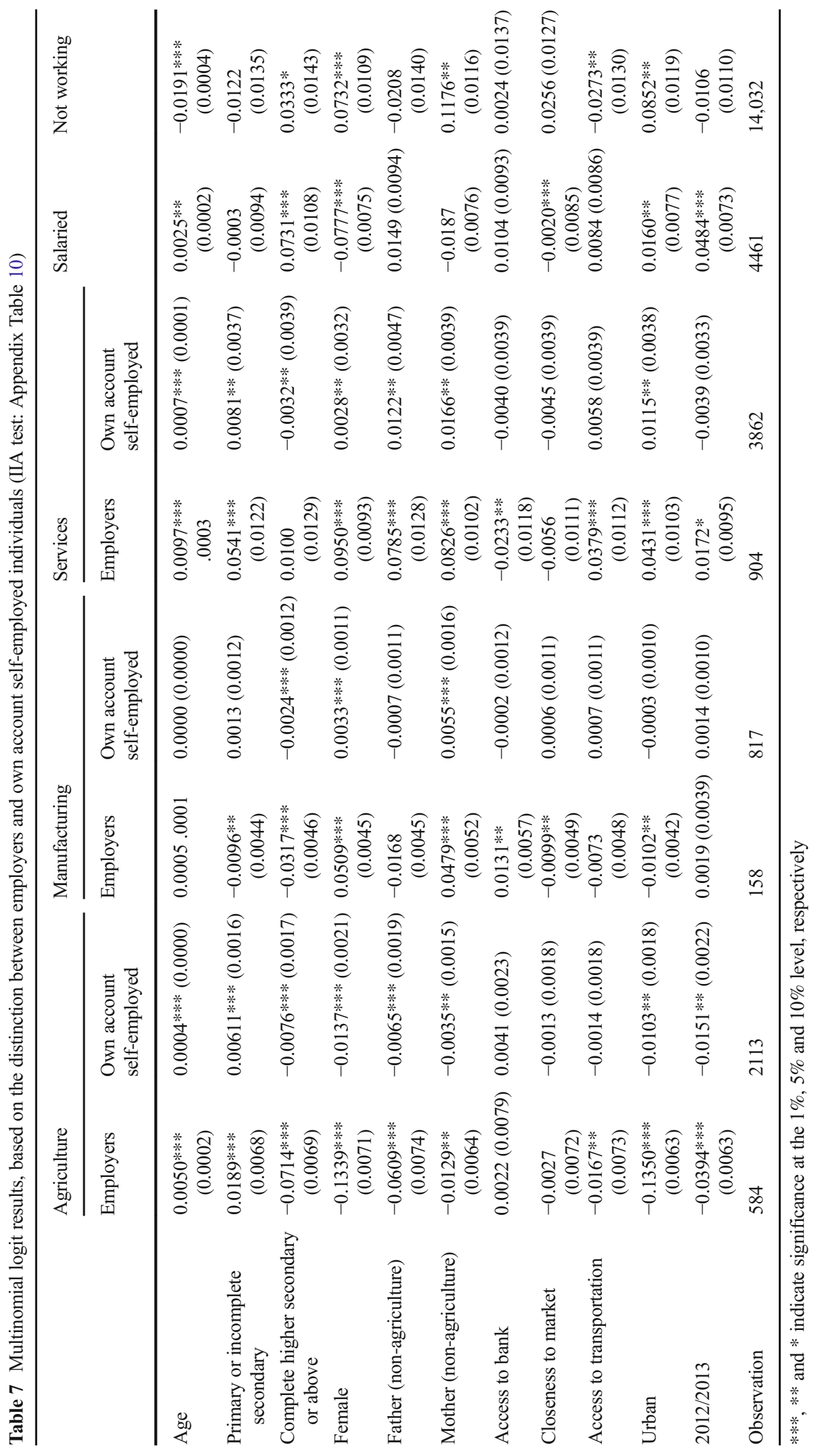




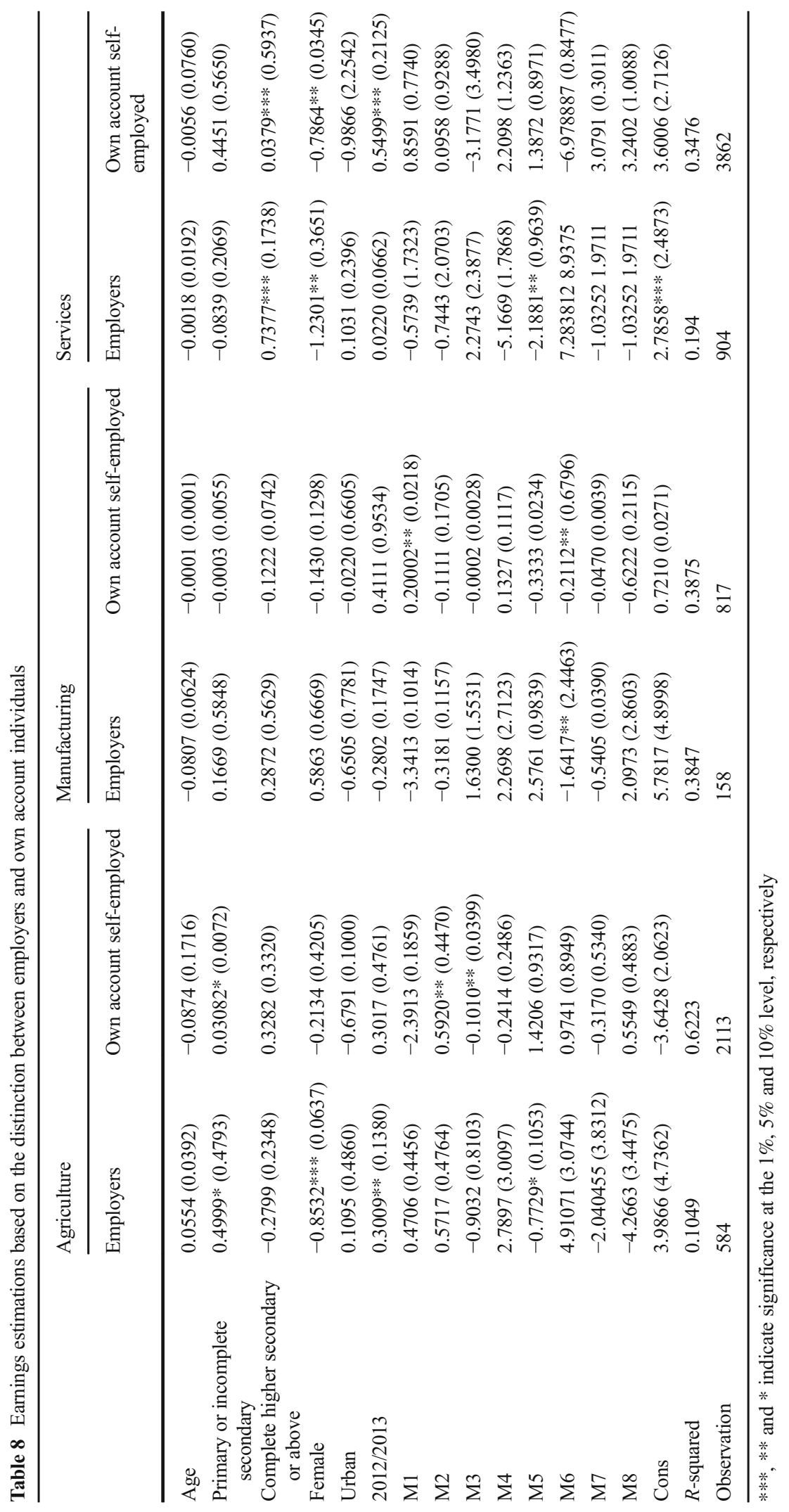


Table 9 Small-Hsiao tests for IIA assumption related to Table 2

\begin{tabular}{llllll}
\hline \multicolumn{2}{l}{ Small-Hsiao tests of IIA assumption } \\
\hline Omitted & $\operatorname{lnL}$ (full) $\operatorname{lnL}$ (omit) & chi $^{2}$ & $d f$ & $P>$ chi $^{2}$ & Evidence \\
\hline 1 & $-25,200$ & 51.843 & 36 & 0.142 & For Ho \\
2 & $-35,400$ & 34.111 & 36 & 0.559 & For Ho \\
3 & $-25,800$ & 46.719 & 36 & 0.109 & For Ho \\
4 & $-27,300$ & 40.86 & 36 & 0.265 & For Ho \\
\hline
\end{tabular}

Table 10 Small-Hsiao tests for IIA assumption related to Appendix Table 7

\begin{tabular}{lllllll}
\multicolumn{2}{l}{ Small-Hsiao tests of IIA assumption } \\
\hline Omitted & $\ln L$ (full) & $\operatorname{lnL}$ (omit) & chi $^{2}$ & $d f$ & $P>$ chi $^{2}$ & Evidence \\
\hline 1 & -5363.931 & -5332.929 & 62.005 & 72 & 0.794 & For Ho \\
2 & -6791.604 & -6760.873 & 61.46 & 72 & 0.808 & For Ho \\
3 & -6185.564 & -6156.299 & 58.529 & 72 & 0.874 & For Ho \\
4 & -7058.544 & -7029.316 & 58.457 & 72 & 0.875 & For Ho \\
5 & -4566.581 & -4534.496 & 64.171 & 72 & 0.733 & For Ho \\
6 & -6615.146 & -6585.604 & 59.085 & 72 & 0.863 & For Ho \\
7 & -5361.787 & -5332.918 & 57.736 & 72 & 0.889 & For Ho \\
\hline
\end{tabular}

credence to an institutional change-driven holistic approach to economic development that creates space for positive synergies between skill generation, on the one hand, and innovation enhancing entrepreneurial activities, on the other. This is consistent with the idea of entrepreneurial and national self-discovery, which provides a broader and more flexible analytical framework than those categorising the links between entrepreneurship and development in concrete stages and proposing one-size-fit-all policy answers.

Open Access This article is distributed under the terms of the Creative Commons Attribution 4.0 International License (http:// creativecommons.org/licenses/by/4.0/), which permits unrestricted use, distribution, and reproduction in any medium, provided you give appropriate credit to the original author(s) and the source, provide a link to the Creative Commons license, and indicate if changes were made.

\section{References}

Ács, Z., \& Naudé, W. (2013). Entrepreneurship, stages of development, and industrialization. In A. Szirmai, W. Naudé, \& L. Alcorta (Eds.), Pathways to industrialization in the 21st century. Oxford: Oxford University Press.
Barungi, B., Ogunleye, E. \& Zamba, C. (2015). Nigeria 2015; African Economic Outlook.

Blanchflower, D. (2004). Self-employment: more may not be better. NBER Working Paper 10286: http://www.nber. org/papers/w10286.pdf.

Böhme, M., \& Thiele, R. (2014). Informal-formal linkages and informal enterprise performance in urban West Africa. The European Journal of Development Research, 26(4), 473489.

Brookings (2015). Industrial clusters: who benefits? https://www. brookings.edu/wp-content/uploads/2015/11/L2CBrief2 agglomeration_FINAL.pdf.

Chen, M. (2014). Informal employment and development: patterns of inclusion and exclusion. The European Journal of Development Research, 26(4), 397-418.

Dimova, R., \& Karim, S. (2016). Inequality of opportunity and (unequal) opportunities in the youth labour market: how is the Arab world different? Geneva: Technical Brief N 6, Work4Youth, International Labour Office.

Dimova, R., Nordman, C., \& Roubaud, F. (2010). Allocation of labor in urban West Africa: insights from the pattern of labor supply and skill premiums. Review of Development Economics., 14(1), 74-92.

Dimova, R., Elder, S., \& Stephan, K. (2016). Labour market transitions of young women and men in the Middle East and North Africa. Geneva: Work4Youth Publication Series \#44, International Labour Office.

Fields, G. (1990). Labor market modeling and the urban informal sector: theory and evidence. In D. Turnham, B. Salomé, \& A. Schwarz (Eds.), The informal sector revisited. Paris: OECD.

Filion, L. J. (1997). Entrepreneurship: entrepreneurs and small business owner-managers. Cahier de recherche-Ecole des hautes études commerciales. Chaire d'entrepreneurship. Maclean Hunter.

Gollin, D., Jedwab, R., \& Vollrath, D. (2015). Urbanization with and without industrialization. Journal of Economic Growth. doi:10.1007/s10887-015-9121-4.

Grimm, M. (2016). What interventions create jobs? Brookings Bloom Roundtable. https://www.brookings.edu/wpcontent/uploads/2016/08/global_20160720_blum_grimm_ v2.pdf

Grimm, M., Van der Hoeven, R., \& Lay, J. (2011). Unlocking potential: tackling economic, institutional and social constriants of informal entrepreneurship in sub-Saharan Africa: main findings and policy conclusions. Social protection and labor. Washington D.C: The World Bank.

Kadiri, I. B. (2012). Small and medium scale enterprises and employment generation in Nigeria: the role of finance. Kuwait Chapter of the Arabian Journal of Business and Management Review., 1(9), 79-93.

Kaldor, N. (1967). Strategic factors in economic development. Ithaca.

Karlan, D. and Morduch, J. (2010). Access to finance. In: Rodrik, D. and Rosenzweig, M. (Eds). Handbook of development economics, volume 5. Amsterdam: Elsevier.

Kerr, W., \& Nanda, R. (2009). Financing constraints and entrepreneurship. Cambridge: National Bureau of Economic Research, Inc.

Kizner, I. M. (1976). Philosophical and ethical implications of Austrian economics. In E. G. Dolan (Ed.), The foundations 
of modern Austrian economics (pp. 75-88). Kansas: Sheed and ward.

Kouakou, C. (2011). Poverty and young urban unemployment in Côte d'Ivoire. Nairobi: AERC Research Paper 240, African Economic Research Consortium.

Maloney, W. (1999). Does informality imply segmentation in urban labor markets? Evidence from sectoral transitions in Mexico. World Bank Economic Review, 13(2), 275-302.

Maloney, W. (2004). Informality revisited. World Development, $32(7), 1159-1178$.

Margolis, D. N. (2014). By choice and by necessity: entrepreneurship and self-employment in the developing world. The European Journal of Development Research., 26(4), 419-436.

Mazumdar, D. (1983). Segmented labor markets in LDCs. American Economic Review, 73(2), 254-259.

Murphy, K.M., Shleifer, A. and Vishny, R.W. (1989). Industrialization and the big push. 97. 1003-1026.

Nieman, G. (2006). Small business management: a South African approach. Pretoria: Van Schaik.

North, D., Wallis, J., \& Weingast, B. (2009). Violence and social orders. Cambridge: Cambridge University Press.

OECD. (1997). OECD economic surveys: the United States 1996/1997. Paris: OECD.

Porter, M., Sachs, J., \& McArthur, J. (2002). Executive summary: competitiveness and stages of economic development. In M. Porter et al. (Eds.), The global competitiveness report 20012002 (pp. 16-26). New York: Oxford University Press.

Poschke, M. (2013). Entrepreneurs out of necessity. A snapshot. Applied Economics Letters, 20(7), 658-663.

Rodrik, D. (2008). Normalizing industrial policy. Working Paper No. 3. Commission on Growth and Development.

Rodrik, D. (2016). Premature deindustrialization. Journal of Economic Growth, 21, 1-3. doi:10.1007/s10887-0159122-3.
Rosenstein-Rodan, P. N. (1943). Problems of industrialisation of Eastern and South-Eastern Europe. The Economic Journal., 53(210/211), 202-211.

Say, J. B. (1836). Traité d'économie politique. Philadelphia: Grigg \& Elliot.

Schumpeter, J. A. (1934). The theory of economic development: an inquiry into profits, capital, credit, interest, and the business cycle. Transaction publishers.

Shirley, M. (2008). Institutions and development. In: Ménard, C. and Shirley, M. (Eds). Handbook of new institutional economics. Springer.

Small and Medium Enterprises Development Agency of Nigeria (2013). National MSME Survey Report, 2013.

Szirmai, A. (2009). Industrialization as an engine of growth in developing countries. UNU-WIDER Working Paper Series, \#2009-010. Maastricht, The Netherlands.

The World Bank. (2008). Finance for all? Policies and pitfalls in expanding access. Washington D.C.: A World Bank Policy Research Report.

The World Bank (2013). The world development report. Jobs. Washington D.C.

The World Bank. (2014). Nigeria economic report 2014. Washington, D.C: The World Bank.

Venter, R., Urban, B., \& Rwigema, H. (2010). Entrepreneurship: theory in practice. Cape Town: Oxford University Press.

World Economic Forum (2017). The global competitiveness report 2016-2017. http://www3.weforum.org/docs/GCR20162017/05FullReport/TheGlobalCompetitivenessReport20162017 FINAL.pdf.

Yusuf, S. (2003). Innovative East Asia: the future of growth. Washington D.C: The World Bank.

Zimmerer, T. W., \& Scarborough, N. M. (2008). Entrepreneurship and new venture formation. New Jersey: Prentice Hall International. 